\title{
DO SOCIAL STUDENTS USE SOCIAL MEDIA MORE OFTEN?
}

\author{
Dr. Ahmet KESICI \\ ORCID: 0000-0003-1830-497X \\ National Education Directorate \\ Siirt, Turkey
}

Received: 13/05/2018 Accepted: 24/07/2018

\begin{abstract}
This study was conducted to determine the change in the sociability levels of high school students depending on the frequency of their using social media and to investigate their social media uses. It employed a mixed-methods research design using both quantitative and qualitative methods together. The sociability levels of 352 students studying in Siirt in 2018 were determined through the "Extraversion" sub-dimension of the Big Five Inventory for this purpose. Accordingly, it was found out that the sociability points of the students differed significantly depending on the frequency of their Youtube, Instagram, and WhatsApp use, but not depending on the frequency of their Facebook use. In addition, the social media uses of the students were investigated with semi-structured interviews made with 27 students who were social and often used social media. In accordance with this aim, the participants were found to use Youtube for entertaining and learning, Instagram for communicating and entertaining, and WhatsApp for communicating. It was concluded in the interviews that the social media uses of the students who often used social media reflect their sociability traits.
\end{abstract}

Keywords: Social media, sociability, Youtube, Instagram, WhatsApp, Facebook.

\section{INTRODUCTION}

That people live in a society, communicate with one another, and establish a relationship with other people is a requisite of human nature. Social relations like belonging to a group, expressing oneself, liking, and being liked are considered among the basic needs of people by Maslow (retrieved from Demirel, 2011). Establishing good relationships with others and maintaining these relationships are considered as essential skills (Bacanl, 1999). Being non-social, being social phobic, shyness, and loneliness are viewed as important problems (Yakut \& Certel, 2016; Bacanlı 1999). According to the multiple intelligence theory, it is mentioned that interpersonal intelligence is related to the fact that an individual communicates with people around him/her, understands their mood, and cooperates with them as a group (Bumen, 2011).

Sociability is regarded as a personality trait in psychology. According to the approach expressing personality, personality is expressed through observable behaviors based on personal differences (Basim, Çetin, and Tabak, 2009). According to this approach, personality is a kind of structure that consists of five dimensions. These dimensions are simply known as extraversion, conscientiousness, agreeableness, neuroticism and openness in the literature. "Five-factor model of personality" was designed according to those five components mentioned in the above sentence (Costa \& McCrae, 1995; Tatlllioglu, 2014). The validiy of this model was maintained by some cross-cultural studies conducted by various scholars (Schmitt, Allik, McCrae, \& Benet-Martinez, 2007). According to this explanation, being social, energetic, cheerful, dominant, assertive, and interested in other people is linked to the extraversion dimension of personality (Costa \& McCrae, 1995; Tathlıoglu, 2014; Aydogmus, 2011). 
Based on the Internet and Internet-based technological developments, the virtual environment entered human life, became an indispensable part of his life, and led to changes and transformations in every aspect of his life. Social relations among people have been moved to the virtual environment through social media tools like Facebook, Instagram, Youtube, and WhatsApp (Hazar, 2011; Evans, 2008). Social media is "any social website which enables users to express themselves, communicate with others, and join groups on the virtual environment as well as contribute to the virtual environment with their thoughts, comments, and broadcasts" (Koksal \& Ozdemir, 2013). Social networks are commonly used all around the world, and their use is increasing rapidly. It was found that the ratio of social media users was $37 \%$ in the 2017 report of We Are Social, the institution doing research on the Internet and digitalization globally, while it increased to $42 \%$ in its January 2018 report. In the June 2017 report of this institution, it was mentioned that the $60 \%$ of the population in Turkey ( 48 million) used social media actively (We Are Social and Hootsuite-a, 2018 and We Are Social and Hootsuite-b, 2018). Kesici (2019) revealed that among social media tools, Youtube, Instagram, WhatsApp, and Facebook were used commonly by high school students.

The use of social media by students is significant for educators and should be investigated. The questions like "Who uses social media more often: social or introvert students, for which purposes do students join social media, and what do students do on social networks?" should be known by educators to renew themselves depending on the changing conditions and to provide proper instruction based on the necessities of the time. Due to this reason, more research on the social media uses of students should be done. These studies can avail educators in different areas like preparing social media-assisted instructional practices and electronic course materials, and in developing distance education programs a lot.

Personality is viewed as an important trait in explaining human behaviors. Mark and Ganzach (2014) told that behaviors in the virtual environment are related to personality depending on the studies made in the literature. Liu et al. (2016) stated that objects like a picture, video, and writing are shared with the approval of personality on social networks and that personality serves as an approval, norm authority in this subject. Based on the studies in the literature, Bai, Zhu, and Cheng (2012) and Tan and Yang (2012) determined that personality can be predicted depending on behaviors on social networks. Settanni, Azucar, and Marengo (2018) revealed that digital tracks can be used to predict personality in their meta-analysis study on the studies having tried to determine personality with the help of individual activities, language, demographic information, and photos, all of which they named as digital tracks in the literature. Owing to this reason, the social media uses of the high school students were investigated based on their sociability levels by considering that social media which enables social networking can be related to sociability in this study. Within this scope, the below questions were aimed to be answered:

$>$ Is there any statistically significant difference between the sociability points of the high school students according to the frequency of their use of Youtube, Instagram, WhatsApp, and Facebook?

$>$ For which purposes do the high school students use social networks for which sociability points significantly differ depending on the frequency of use?

\section{METHODOLOGY}

This study was conducted as a mixed-methods study using the quantitative (general survey model) and qualitative (case study) methods. Therefore, it was aimed to understand the subject better by making use of the advantages of both methods (Creswell, 2003). The frequency of social media uses was compared depending on the students' levels of sociability with general survey model in the quantitative dimension of the study (Karasar, 2014). It was investigated in detail how the students used the social networks for which significant differences were found among the sociability points based on the frequency of social media uses 
with case study in the qualitative part (Buyukozturk et al., 2010). Because of this reason, semi-structured interviews were made.

\section{Participants}

\section{Participants of the Quantitative Part}

352 high school students (177 male, 175 female) studying in the 9th, 10th, and 11th grades in Siirt in the 2017-2018 education year participate into the study. To provide data variety, one religious high school, one vocational high school, and two Anatolian high schools were chosen randomly and included in the study. The number of the participants depending on the type of the schools are indicated in Table 1.

Table 1. The distribution of the participants based on the types of the schools

\begin{tabular}{lcc}
\hline School & $f$ & $\%$ \\
\hline Religious High School & 104 & 29.5 \\
Vocational High School & 80 & 22.7 \\
Anatolian High School & 168 & 47.7 \\
\hline
\end{tabular}

\section{Participants of the Qualitative Part}

27 students chosen through criterion sampling participated into the qualitative part of the study. Nine students at a time (two from the vocational high school, two from the religious high school, five from Anatolian high school) joined the study for Youtube, Instagram, and WhatsApp. To choose the participants, the frequent use of social networks, being considered as social based on teacher observations, and having high sociability points (above 3.99 out of 5.00) were used.

\section{Data Collection Tools}

Information Sheet

The information sheet was used to find out the frequency of social network uses of the students.

\section{Extraversion Personality Scale}

The sociability levels of the participants were determined through the 8-item extraversion sub-dimension of "The Big Five Inventory" (BFI) developed by Benet-Martinez and John in 1998 as a 44-item and 5point Likert-type scale. 5FI was adapted to Turkish by Sumer and Sumer (2005) within the scope of the study of Schmitt et al. (2007) which aimed to identify the self-definition profiles of the individuals in 56 countries (as cited in Basım, Çetin \& Tabak, 2009). In this study, Cronbach's alpha coefficient of the extraversion sub-dimension was calculated .721.

\section{Semi-Structured Interview Forms}

Three interview forms were prepared by considering the features of Youtube, Instagram, and WhatsApp within the scope of the study to investigate the students' uses of social media. Two information technologies teachers and one academician with a Ph.D. degree and experience in the use of educational technology were consulted in preparing the interview forms. Pre-test was made before the implementation of the interviews. The initial interviews for each social network were made with one student at a time, and the interview forms were modified in accordance with the pre-tests of the forms. The data collected in the pre-tests were not included in the study.

\section{Data Analysis}

\section{The Analysis of the Quantitative Data}

The quantitative data were analyzed with SPSS. The normality of the sociability point sets based on the frequency of Youtube, Instagram, WhatsApp, and Facebook use was investigated by calculating the coefficients of kurtosis and skewness. As the coefficients of kurtosis and skewness of all point sets were higher than -1 and lower than +1 , and the Q-Q and histogram graphics of each point set complied with 
the normality, it was decided that the point sets were distributed normally. Because of this finding, parametric tests were applied the data. The homogeneity of the groups was evaluated with Levene test. It was found that the groups for Facebook were not homogeneous $(\mathrm{p}<.05)$, but the groups for the other social networks were homogeneous ( $\mathrm{p}>.05$ ). As a result, the sociability points depending on the frequency of Facebook use were compared with Brown-Forsythe, while the sociability points for other social networks were compared with one-way analysis of variance. The source of the difference was identified with a post hoc test, Scheffe Test, and the effect size was measured with Eta-squared $\left(\eta^{2}\right)$ (Can, 2014; Buyukozturk, 2011).

\section{The Analysis of the Qualitative Data}

The qualitative data were analyzed through descriptive and content analysis. The qualitative data were reported directly to present them to the readers in an organized way. In addition, several themes were developed by analyzing the participants' views (Yıldırım and Simsek, 2011). Coding was made separately by the researcher and another one who was experienced in qualitative research. The conflicting issues were corrected by consulting an academician. The reliability of coding in the content analysis was measured with the formula of reliability proposed by Miles and Huberman (1994), and the coefficients of reliability for Youtube, Instagram, and WhatsApp were measured 0.91, 0.90, and 0.95 successively.

\section{Limitation}

This study has been limited by using only Youtube, Instagram, WhatsApp, and Facebook among social networks.

\section{FINDINGS}

\section{Findings Related to Youtube Use}

The Comparison of the Sociability of the Participants Depending on the Frequency of Their Youtube Use

The students' sociability points depending on the frequency of their Youtube use were compared with one-way analysis of variance. The results are shown in Table 2 .

Table 2. The results of one-way analysis of variance made to compare the sociability points depending on the frequency of Youtube use

\begin{tabular}{llccccccc}
\hline Social Network & Frequency & $\mathrm{N}$ & $\overline{\mathrm{x}}$ & sd. & $\mathrm{F}$ & $\mathrm{p}$ & $\begin{array}{c}\text { Significant } \\
\text { Difference }\end{array}$ & $\eta^{2}$ \\
\hline \multirow{3}{*}{ Youtube } & Never $^{1}$ & 52 & 2.92 & .51 & 13.106 & .000 & $1-2^{*}$ & 0.069 \\
& $\mathrm{~A} \mathrm{little}^{2}$ & 160 & 3.26 & .58 & & & $1-3^{*}$ & Medium \\
& $\mathrm{A} \mathrm{lot}^{3}$ & 140 & 3.49 & .59 & & & $2-3^{*}$ & \\
\hline
\end{tabular}

As seen in Table 2, the averages of the sociability points of the students based on the frequency of Youtube use are differed significantly $(\mathrm{p}<.05)$. The average sociability point of the students using Youtube a lot is significantly higher than the point of the students who use Youtube a little and never use it. The average sociability point of the students using Youtube a little is significantly higher than the average point of the students who never use Youtube. A medium effect size for Youtube use was measured $\left(\eta^{2}=.069\right)$.

\section{The Students' Purposes of Using Youtube}

The students were asked what their purposes for using Youtube were in the semi-structured interviews. The results of the content analysis of the answers to this question are presented in Table 3. 
Table 3. The students' purposes of using Youtube

\begin{tabular}{ll}
\hline Theme & $f$ \\
\hline Information & 2 \\
Lesson & 3 \\
Entertainment & 6 \\
Curiosity & 2 \\
\hline
\end{tabular}

As seen in Table 3, the students' purposes for using Youtube were investigated under four themes: information, lesson, entertainment, and curiosity. The participants mentioned that Youtube was beneficial to them in line with their purposes of using it. Some samples for the students' views on this subject are presented below.

S10. "It enables me to learn the subjects that I cannot learn at school."

S11. "I make use of my free time on Youtube."

S15. "I spend enjoyable time on Youtube."

S16. "There is nothing like Youtube in relishing."

S18. "I sometimes learn information about different topics by watching informational videos."

\section{The Content of the Videos That the Participants Watch on Youtube}

The participants were asked what kind of videos they watched. The results of the content analysis of the participants' answers to this question are given in Table 4.

Table 4. The content of the videos the participants preferred to watch on Youtube

\begin{tabular}{ll}
\hline Theme & $f$ \\
\hline Game & 2 \\
Education/Information & 6 \\
Entertainment & 5 \\
Series/Song & 4 \\
Fear/ Adventure/Excitement & 5 \\
\hline
\end{tabular}

As seen in Table 4, the content of the videos the students preferred watching on Youtube includes game, education/information, entertainment, series/song, fear, adventure/excitement. It is understood that the students use Youtube with the motivation of entertainment more.

\section{The Participants' Following Youtube Channels and Attitudes toward the} Recommended Videos

The students were asked whether they followed any Youtube channel and if so, why they followed them in the study. All students mentioned that they followed several Youtube channels. The students explained the reason of watching Youtube channels as they liked the characters on the videos and found them sympathetic. The sample quotations for the explanations of some students on the subject are given below.

S18. ".....I follow channels. Because these people are the ones that I really like."

S17. "They give information in an enjoyable way."

S15. "... I watch. Because they are sympathetic."

S11. "... They teach very well."

S10. "They make enjoyable and entertainment videos."

The participants were asked whether they watched the recommended videos on Youtube. All participants told that they watched the recommended videos. The students stated that they followed the videos since they wondered the ones liked most and believed that these videos were the good ones. Several examples of the answers of the participants on this subject are presented below. 
S10. "To follow what happens in Turkey."

S13. "Because I wonder, I watch"

S15. "If a video is recommended, it is a good one."

S16. "Because they are popular"

\section{Findings Related to Instagram Use}

The Comparison of the Sociability Points of the Participants Depending on the Frequency of Their Instagram Use

One-way analysis of variance was used to compare the students' average sociability points based on the frequency of their Instagram use. The results are presented in Table 5.

Table 5. The results of one-way analysis of variance made to compare the sociability points depending on the frequency of Instagram use

\begin{tabular}{llccccccc}
\hline Social Network & Frequency & $\mathrm{N}$ & $\overline{\mathrm{x}}$ & $\mathrm{sd}$ & $\mathrm{F}$ & $\mathrm{p}$ & $\begin{array}{c}\text { Significant } \\
\text { Difference }\end{array}$ & $\eta^{2}$ \\
& Never $^{1}$ & 108 & 3.16 & .70 & 7.302 & .001 & $1-3^{*}$ & 0.04 \\
\multirow{2}{*}{ Instagram } & $\mathrm{A} \mathrm{little}^{2}$ & 103 & 3.21 & .73 & & & $2-3^{*}$ & Low \\
& $\mathrm{A} \mathrm{lot}^{3}$ & 141 & 3.48 & .70 & & & & \\
\hline
\end{tabular}

As seen in Table 5 , there are statistically significant differences among the average sociability points of the students depending on the frequency of Instagram use $(\mathrm{p}<.05)$. The average sociability point of the students using Instagram a lot is significantly higher than the average points of the students who use Instagram a little and never use it. A low effect size for Instagram use was measured $\left(\eta^{2}=.04\right)$.

\section{The Participants' Purposes of Using Instagram}

The students were asked what their purposes for using Instagram were in the interviews. Their answers were content-analyzed. According to this analysis, it was found that the students used Instagram with social motivation and the motivation of entertainment. The results of the content analysis are mentioned in Table 6.

\begin{tabular}{ll} 
Table 6. The students' purposes of using Instagram \\
\hline Theme & $f$ \\
\hline To entertain & 3 \\
To spend time & 1 \\
To follow friends & 4 \\
To learn information & 3 \\
To keep up with the time & 2 \\
To be social/make new friends & 2 \\
\hline
\end{tabular}

As seen in Table 6, the purposes of the participants for using Instagram were investigated under six themes: to entertain, to spend time, to follow friends, to learn information, to keep up with the time, and to be social/make new friends.

\section{How the Participants Used Instagram?}

The participants were asked what they did on Instagram, and the students' answers for this question were content-analyzed. The obtained results are presented in Table 7. 
Table 7. The students' purposes of using Instagram

\begin{tabular}{ll}
\hline Theme & $f$ \\
\hline To share photographs & 6 \\
To share what they do (visits, clothes, food, etc.) & 2 \\
To share bywords & 3 \\
\hline
\end{tabular}

As seen in Table 7, the participants told that they used Instagram to share something about themselves. The views of the participants were assembled under three themes: to share photographs, to share what they did, and to share bywords.

\section{The Participants' Social Relations on Instagram}

The participants were asked how many people they followed and how many people followed them on Instagram. It was found that the number of the people the students followed was between 115 and 400, and that the number of their followers was between 121 and 400. The participants were asked who they followed. The results of the content analysis of the answers given are presented in Table 8 .

Table 8. People the participants followed on Instagram

\begin{tabular}{ll}
\hline Theme & $f$ \\
\hline Friends & 5 \\
Family & 2 \\
Acquaintances & 4 \\
Celebrities/Phenomenon & 3 \\
\hline
\end{tabular}

As seen in Table 8, the people whom the students followed were investigated under four themes: friends, family, acquaintance, and celebrities. The participants were asked what they thought about whether Instagram was a relevant tool to maintain friendship. All students stated that it was a very relevant tool to maintain their relations. The students mentioned that they could maintain their friendship, enhance it, and make new friends. The sample answers of some participants on this subject are presented below.

S19. "I can follow and message my friends who I cannot meet face to face."

S20. "We can meet our friends whom we have left because of school and work."

S21. "I met some of my friends on Instagram."

S23. "I can make friends with different people from different places through Instagram."

S24. "We can solve our problems by messaging our friends on Instagram"

S25. "I can know my friends better with Instagram."

\section{Findings Related to WhatsApp Use}

The Comparison of the Sociability Points of the Participants Depending on the Frequency of Their Whatsapp Use

One-way analysis of variance was used to compare the students' average sociability points depending on their frequency of WhatsApp use. The results are presented in Table 9.

Table 9. The results of one-way analysis of variance made to compare the sociability points depending on the frequency of WhatsApp use

\begin{tabular}{llccccccc}
\hline \multirow{2}{*}{ Social Network } & Frequency & $\mathrm{N}$ & $\overline{\mathrm{x}}$ & $\mathrm{sd}$. & $\mathrm{F}$ & $\mathrm{p}$ & $\begin{array}{r}\text { Significant } \\
\text { Difference }\end{array}$ & $\eta^{2}$ \\
\hline \multirow{3}{*}{ WhatsApp } & Never $^{1}$ & 90 & 3.06 & .75 & 16.246 & .000 & $1-3^{*}$ & 0.085 \\
& $\mathrm{~A} \mathrm{little}^{2}$ & 141 & 3.22 & .69 & & & $2-3^{*}$ & Medium \\
& $\mathrm{A} \mathrm{lot}^{3}$ & 119 & 3.58 & .64 & & & & \\
\hline
\end{tabular}


As seen in Table 9, there are statistically significant differences among the average sociability points of the students depending on the frequency of WhatsApp use $(\mathrm{p}<.05)$. The average sociability point of the students using WhatsApp a lot is significantly higher than the average points of the students who use WhatsApp a little and never use it. A medium effect size for WhatsApp use was measured $\left(\eta^{2}=.085\right)$.

\section{The Participants' Purposes of Using Whatsapp}

The students were asked what their purposes for using WhatsApp were in the interviews. Their answers were content-analyzed, and the results of the content analysis are presented in Table 10.

Table 10. The students' purposes of using WhatsApp

\begin{tabular}{ll}
\hline Theme & $f$ \\
\hline Communication & 6 \\
Share & 3 \\
Chat & 4 \\
\hline
\end{tabular}

As seen in Table 10, the students told that they used WhatsApp to communicate, share, and chat.

The Number of the Groups which the Students were the Members of and Their Friendship

The students were asked whether they were the members of any group on WhatsApp. All students said that they were the members of at least one group on WhatsApp. The data about the numbers of the groups which the students were the members of are shown in Table 11.

Table 11. The numbers of the groups which the students were members of on WhatsApp

\begin{tabular}{ll}
\hline The number of the groups & $f$ \\
\hline $1-2$ groups & 3 \\
$3-5$ groups & 2 \\
6 groups and more & 4 \\
\hline
\end{tabular}

As seen in Table 11, it was determined that all students were members of at least one group on WhatsApp, and that several students were members of more than one group. All students mentioned that WhatsApp was a suitable platform to maintain friendship and that they communicated and shared with their friends on this platform. The sample answers of several students on this subject are mentioned below.

S2. "I can communicate with my friends who are not very close to where I live. I also share the things like picture, audio, and video with my group friends as a whole"

S3. "WhatsApp gives us the opportunity to video chat"

S5. 'I communicate with my friends whom I was always with, but moved to a different place and who I care with WhatsApp."

S6. "I maintain my friendship through WhatsApp on my holidays."

S9. "Thanks to WhatsApp, I do not lose my connection with my friends"

\section{Findings Related to Facebook Use}

\section{The Comparison of the Sociability Points of the Participants Depending on the} Frequency of Their Facebook Use

The students' average sociability points based on the frequency of their Facebook use were compared with Brown-Forsythe test in the study. The results are presented in Table 12. 
Table 12. The results of Brown-Forsythe test made to compare the sociability points depending on the frequency of Facebook use

\begin{tabular}{llccccc}
\hline Social Network & Frequency & $\mathrm{N}$ & $\overline{\mathrm{x}}$ & sd. & $\begin{array}{c}\text { Brown-Forsythe } \\
\text { Statistic }\end{array}$ & $\mathrm{p}$ \\
\hline \multirow{3}{*}{ Facebook } & Never $^{1}$ & 203 & 3.28 & .79 & .243 & .784 \\
& $\mathrm{~A} \mathrm{little}^{2}$ & 112 & 3.33 & .63 & & \\
& $\mathrm{~A} \mathrm{lot}^{3}$ & 37 & 3.34 & .60 & & \\
\hline
\end{tabular}

As seen in Table 12, there is not any statistically significant difference among the average sociability points of the students according to the frequency of Facebook use ( $p>.05)$.

\section{DISCUSSIONS AND CONCLUSION}

This study investigated the sociability of the high school students depending on the frequency of their social media use. It was found in the study that the sociability points of the high students differ significantly based on the frequency of Youtube use. The students using Youtube a lot were found out to be more social than the ones using Youtube a little and never using it, and the students using Youtube a little more sociable than the ones who never used it. Corroborating this finding, Biel, Aran, and GaticaPerez (2011) mentioned in their study that Youtube is a relevant tool to predict sociability (extraversion). It was revealed in the interviews that the students used Youtube for entertaining, studying a lesson, and learning information about the subjects that they wondered. The students told that they used Youtube for playing games, watching series, listening to music, and watching adventure and horror videos to entertain. For this purpose, they said that they followed some video channels on Youtube. The participants explained that the video channels they followed caught their attention because the channels had entertaining, popular, and sympathetic individuals. Depending on these findings, it can be said that Youtube users have an extravert, excited, energetic, enjoyable, and curious personality. These features are the traits of a social person (Aydogmus, 2011; Costa \& McCrae, 1995; Beder, 2015).

It was found in the study that there are statistically significant differences between the sociability points of the students in accordance with the frequency of Instagram use. It was concluded that the students using Instagram a lot are more social than the ones who use it a little and never use it. In line with this finding, Ferwerda, Schedl, and Tkalcic (2015) discovered that the shares on Instagram are related to some personal traits including extraversion. It was found in the interviews that the students used Instagram for entertaining, maintaining their friendship, learning information, and keeping up with the time. The number of the people the participants followed and the number of their followers are very high. The students told that they followed their relatives, friends, and acquaintances as well as the celebrities they wondered. The participants stated that they shared their own photos, the clothes they wore, the food they ate, bywords, and some images belonging to their social life as well as sent messages in order to influence other people. The students mentioned that they could maintain their friendship by communicating with their friends that they could not meet face to face. According to this finding, the participants can be said to be people who are always in communication with the people in their social environment, like this, and prefer staying in big groups. These features are some of the certain traits of social individuals (Stevens, 2001; Aydogmus, 2011).

It was revealed in the study that there are statistically significant differences between the sociability points of the high students based on the students' frequency of WhatsApp use. It was determined that the students using WhatsApp a lot are more social than the ones who use it a little and never use it. Supporting this finding, Montag et al. (2015) revealed that there is a low level and statistically significant relation between WhatsApp use and extraversion. Stachl et al. (2017) discovered that such uses as calling, communicating, and sharing photos on smartphones are related to sociability. That these practices can be 
done with WhatsApp and that WhatsApp is commonly and intensively used on smartphones indicate that WhatsApp use can be related to sociability. The students mentioned in the interviews that they used WhatsApp for communication, share, and chat. The students told that they used WhatsApp to maintain their friendship and created friend groups on WhatsApp. Even several students stated that they were members of more than six groups. It can be said that WhatsApp strengthens friendship through its video call service. In addition, the participants were thought to be very social and hot-blooded by considering their purposes of using WhatsApp. These features are some of the certain traits of sociability (Costa \& McCrae, 1995).

It was found in the study that there are no statistically significant differences between the sociability points of the high students depending on the frequency of their Facebook use. There are several studies supporting this finding in the literature (Ross et al., 2009; Skues, Williams \& Wise, 2012). Yet, there are some other studies conflicting with this finding (Ryan \& Xenos, 2011, Kosinski et al., 2014, Quercia et al., 2012).

It was understood in the study that the high students preferred using Instagram which has similar features with Facebook to using Facebook. It is simple to use Instagram. It enables to view low-quality photos taken with a mobile phone as professional photos. It also enables to upload photos and videos faster. In addition, it provides the opportunity to share photos on different social network platforms at the same time (Kurcaburun, 2017). These features are thought to result in the preference of students to use Instagram. It was concluded in the study that sociality had a medium impact on the frequency of use of Youtube and WhatsApp social sites as well as having a low level of impact on the frequency of use of Instagram. These findings might suggest that Youtube and WhatsApp applications seem to be easier than Instagram in terms of usage. For this reason, it might be advisable to design technological tools and systems which are of easy use and not too complicated for students.

The social students were determined to use Youtube, Instagram, and WhatsApp more often than other social networks. This result supports the view that the behaviors on the virtual environment are related to personality and are affected by personality. The relationship between personality and the behaviors of virtual worlds of individuals are of great interest among academicians. This phenomenon has been generally analyzed in terms of interdisciplinary approaches and particularly psychology. Scholars aim at finding clues to create and advertise appropriate products for individuals by determining their behaviors in virtual worlds or being able to reach beneficial outcomes as for commercial or health concerns like identifying some individuals in advance who have the possibility of committing suicides and are victims to get down to having depression (Bai, Zhu \& Cheng, 2012; Settanni, Azucar \& Marengo, 2018). In this respect, the studies conducted especially for educational grounds may contribute a lot to design or improve educational materials or systems according to individual differences of people. Due to this reason, the personality traits of students should be considered to achieve the success in using technology in education and in integrating technology with education. More studies should be also made on this subject. When considering the motivations of the social students in the study, it can be said that entertainment, excitement, and interaction should not be neglected in educational materials to be prepared. Besides, aesthetics and visuality should be paid attention in lesson presentations and electronic, educational materials. It can be concluded that social students can have successful results in social media-based instructional practices. That educator's use social media in collaborative instructional practices and other educational practices like project and performance assignments can be beneficial to social students. However, social students can be said to be more vulnerable to digital addiction like social media addiction. Because of this reason, it is thought that the awareness of students, especially social students should be raised on the conscious use of technology and digital addiction. 


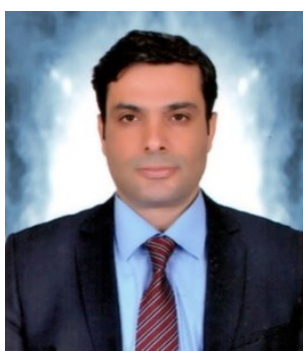

Ahmet KESICI is a math teacher. He works in Siirt. Dr. Kesici graduated from Harran University, department of Mathematics. He received his MS in Mathematics Education Department at Yuzuncu Yll University and Ph.D. in Curriculum and Instruction Department at Dicle University. His academic interest areas are math education, social technologies, e-learning and digital addiction. $\mathrm{He}$ has many articles published in academic journals.

\section{Ahmet KESICI}

National Education Directorate

Address: National Education Directorate, 56100, Siirt, Turkey

E-mail: ahmetkesici@yahoo.com

\section{REFERENCES}

Aydogmus, C. (2011). The impacts of follower psychological empowerment and perceptions of transformational leadership on the relationship between follower personality and job satisfaction (Unpublished doctoral thesis). Hacettepe University, Ankara.

Bacanl, H. (1999). Sosyal beceri egitimi (Social skills training). Ankara, Nobel.

Basım, H. N., Çetin, F., \& Tabak, A. (2009). The relationship between big five personality characteristics and conflict resolution approaches. Turkish Journal of Psychology, 24 (63), 35-37.

Beder, N. (2015). The mediating role of personality characteristics of five factors and academic level of perception of sely-efficacy in effect of socio-economic status to academic achievement: A study on university students (Unpublished Master's Thesis). Turkish Military Academy, Ankara.

Bai, S., Zhu, T., \& Cheng, L. (2012). Big-five personality prediction based on user behaviors at social network sites. arXiv preprint arXiv:1204.4809.

Biel, J. I., Aran, O., \& Gatica-Perez, D. (2011, July). You Are Known by How You Vlog: Personality Impressions and Nonverbal Behavior in YouTube. In ICWSM.

Bumen, N. T. (2011) Coklu zeka kuramı [Multiple intelligence theory]. O. Demirel (Ed.), Egitimde yeni yonelimler [New trends in education]. Ankara: Pegem Academy Publishing.

Buyukozturk, S., Kılıc-Cakmak, E., Akgun, O. E., Karadeniz, S., \& Demirel, F. (2010). Bilimsel Arastirma Yontemleri [Scientific research methods], (6 ${ }^{\text {th }}$ Ed.). Ankara: Pegem Akademi Yayıncilık.

Buyukozturk, S. (2011). Sosyal bilimler icin veri analizi el kitabı [Manual of data analysis for social sciences] (15 $5^{\text {th }}$ Ed.). Ankara: Pegem Akademi.

Can, A. (2014). SPSS ile bilimsel arastırma surecinde nicel veri analizi [Quantitative data analysis in scientific research process with SPSS] (3 ${ }^{\text {rd }}$ Ed.). Ankara: Pegem Akademi.

Costa, Jr. P.T. \& McCrae, R.R. (1995). Domains and facets: Hierarchical personality assessment using the revised NEO personality inventory. Journal of Personality Assessment, 64(1): 21-50.

Creswell, J. W., Plano Clark, V. L., Gutmann, M. L., \& Hanson, W. E. (2003). Advanced mixed methods research designs. In Tashakkori, A. and Teddlie, C. (Ed.), Handbook of mixed methods in social and behavioral research (p. 209-240). CA: Sage. 
Demirel, O. (2010). Kuramdan uygulamaya eğitimde program geliştirme [Curriculum development in education from theory to practice] (16 ${ }^{\text {th }}$ Ed.). Ankara: Pegem Academy Publishing.

Evans, D. (2008). Social media marketing an hour a day. Wiley Publishing Inc, Indiana.

Ferwerda, B., Schedl, M., \& Tkalcic, M. (2015, September). Predicting personality traits with instagram pictures. In Proceedings of the 3rd Workshop on Emotions and Personality in Personalized Systems 2015 (pp. 7-10). ACM.

Hazar, M. (2011). Social media dependency-Filed survey. Gazi Universitesi lletisim Fakultesi, 32,151.

Karasar, N. (2014). Bilimsel arasturma yontemi [Scientific research method]. Ankara: Nobel.

Kesici, A. (2019). Examination of high school students' attitudes for the educational use of social networks based on the frequency of social networks usage. Journal of Uludag University Faculty of Education. (Articles in press).

Kircaburun, K. (2017). Investigation of the relationship between self-liking, big five personality and Instagram addiction among university students (Unpublished Master's Thesis).Sakarya University, Sakarya.

Kosinski, M., Bachrach, Y., Kohli, P., Stillwell, D., \& Graepel, T. (2014). Manifestations of user personality in website choice and behaviour on online social networks. Machine learning, 95(3), 357-380.

Koksal, Y., \& Ozdemir, S. (2013). An investigation on place of social media in promotion mix. Suleyman Demirel University The Journal of Faculty of Economics and Administrative Sciences, 18(1).

Liu, L., Preotiuc-Pietro, D., Samani, Z. R., Moghaddam, M. E., \& Ungar, L. H. (2016, May). Analyzing Personality through Social Media Profile Picture Choice. In ICWSM (pp. 211-220).

Mark, G., \& Ganzach, Y. (2014). Personality and internet usage: A large-scale representative study of young adults. Computers in Human Behavior, 36, 274-281.

Miles, M. B., \& Huberman, A. M. (1994). Qualitative data analysis. Thousand Oaks, CA: Sage Publication.

Montag, C., Błaszkiewicz, K., Sariyska, R., Lachmann, B., Andone, I., Trendafilov, B., ... \& Markowetz, A. (2015). Smartphone usage in the 21st century: who is active on WhatsApp? BMC research notes, 8(1), 331.

Ross, C., Orr, E.S., Sisic, M., Arseneault, J.M., Simmering, M.G. and Orr, R.R. (2009) Personality and motivations associated with facebook use. Computers in Human Behavior, 25, 578-586.

Ryan, T. and Xenos, S. (2011). Who Uses Facebook? An investigation into the relationship between the big five, shyness, narcissism, loneliness, and Facebook usage. Computers in Human Behavior, 27, 1658-1664.

Settanni, M., Azucar, D., \& Marengo, D. (2018). Predicting individual characteristics from digital traces on social media: A meta-analysis. Cyberpsychology, Behavior, and Social Networking, 21(4), 217228.

Schmitt, D.P., Allik, J., McCrae, R.R. \& Benet-Martinez, V. (2007). The geographic distribution of big fi ve personality traits: Patterns and profiles of human self-description across 56 nations. Journal of Cross-Cultural Psychology, 38 (2), 173-212.

Skues, J.L., Williams, B. and Wise, L. (2012). The effects of personality traits, self-esteem, loneliness, and narcissism on Facebook use among university students. Computers in Human Behavior, 28, 2414-2419. 
Stachl, C., Hilbert, S., Au, J. Q., Buschek, D., De Luca, A., Bischl, B., ... \& Buhner, M. (2017). Personality traits predict smartphone usage. European Journal of Personality, 31(6), 701-722.

Stevens, C. D. (2001). Selecting employees for fit: Personality and preferred managerial style. Journal of Managerial Issues, 13 (4), 500-517.

Tan, W. K., \& Yang, C. Y. (2012). Personality trait predictors of usage of Internet services. In Int Conf Econ Bus Innovation (Vol. 38, p. 185e9).

Tatlilıglu, K. A. (2014). A research subscales of undergraduates' personality traits according to five factor personality theory in terms of some variants. Journal of History School (JOHS), 7(17), 939-971.

Quercia, D., Lambiotte, R., Stillwell, D., Kosinski, M., \& Crowcroft, J. (2012, February). The personality of popular facebook users. In Proceedings of the ACM 2012 conference on computer supported cooperative work (pp. 955-964). ACM.

We Are Social and Hootsuite-a. (2018, March 17). Retrieved from https://wearesocialnet.s3.amazonaws.com/wp-content/uploads/2018/01/DIGITAL-IN-2018-002-TIME-SPENTON-THE-INTERNET-V1.00.png

We Are Social and Hootsuite-b. (2018, March 17). Retrieved from https://wearesocialnet.s3.amazonaws.com/uk/wp-content/uploads/sites/2/2017/01/Slide007.png

Yakut, S., \& Certel, H. (2016). Investigation the different variables of solitude among teachers. Individual and Society Journal of Social Science, 6(1), 69-94.

Yıldırım, A., \& Simsek, H. (2011). Sosyal bilimlerde nitel arastırma yontemleri (Qualitative research methods in the social sciences). Ankara: Seckin. 